\title{
Sınırdurum Kişilik Organizasyonunun ve Depresif Semptomların Sullivan'ın Kişilerarası Teori'si Açısından Yorumlanması: Terapistin Katılımcı Gözlemci Rolü
}

\author{
Uzm. Psk. Tuğba Uyar Suiçmez* \\ Orta Doğu Teknik Üniversitesi
}

\begin{abstract}
$\ddot{O} z$
İnsan bir varlık olarak temelde birtakım arzuların doyurabilmek, gerilim hissini azaltabilmek ve daha anlamlı bir etkileşim ve çevre sağlayabilmek için kişilerarası ilişki kurmaya ihtiyaç duymaktadır (Sullivan, 1953). Terapi sürecinde de danışanın hayatında oluşturduğu kişilerarası ilişkileri incelemek ve şikâyetleri bu etkileşimler çerçevesinde konumlandırmak önemli bir yer kaplamaktadır. Bu süreçte terapist ile danışan arasında kurulan ilişki bahsi geçen ilişkilerin incelenmesinden elde edilen verilerin işleneceği ve yeni doğrulayıcı duygusal deneyimlerin oluşturulacağı sağlıklı ve güvenli bir alan işlevine sahiptir. Bu noktada da Sullivan'ın "katılımcı gözlemci" adını verdiği pozisyon terapist ile danışan arasında kurulan ilişkinin yeni deneyimler yaratmasının zeminini hazırlamaktadır. Bu makalede, istikrarsız kendilik imajı, değişken duygular, dönemsel olarak artan depresif semptomlar ve dürtüsel davranışlar, kişilerarası ilişkilerde bozulmalar ve ayrılma-bireyleşme meselelerinde yaşadığı zorluklardan şikâyetçi olan vaka genel özellikleriyle özetlenmiş ve terapi süreci Sullivan'ın kişilerarası teorisi açısından ele alınmıştır. Terapi süreci, terapist ile hasta arasında kurulan ilişki ve bu ilişkinin işlemlenmesi üzerinden vakanın şikâyetlerinin özelliklerini ve bunları sürdüren faktörleri anlamayı ve şikâyetlerinde de gerileme sağlayacak olan kişilerarası ilişkilerini geliştirmeyi amaçlamıştır.
\end{abstract}

Anahtar Sözcükler: Sullivan, doğrulayıcı duygusal deneyim, sınırdurum kişilik organizasyonu, depresif semptomlar 


\title{
An Interpretation of Borderline Organization in Personality and Depressive Symptoms with Regard to Sullivan's Interpersonal Theory: The Participant Observer Role of Therapist
}

\author{
Tuğba Uyar Suiçmez, M. A.* \\ Middle East Technical University
}

\begin{abstract}
Sullivan (1953) explained that human being needs an interpersonal relationship in order to satisfy desires, decrease tension and create a meaningful world. The interpersonal relationships are the main tasks in continuing the life. Moreover, the relationship between the therapist and the client is the new area which could help both the client and the therapist create new experiences. The participant observer role of the therapist would be expected to function as a tool for creating new corrective experiences. Using the therapist client relation in order to create a new healthy and corrective emotional expressions and experiences was planned to be the main tool in therapy process. In this article the case of Ms. B and therapy process were discussed according to the Sullivan's Interpersonal theory especially based on corrective emotional experience notion. Instability in self image and affects, and impairments in the area of interpersonal functioning, showing depressive symptoms, increment in impulsivity, showing risk taking behaviors and struggles related to separation individuation issues are some of the symptoms that Miss. B. complained. Those complaints were related to depressive symptoms which have been continued for approximately 8 years and borderline level organization of her personality. Ms. B has a quite long psychiatric treatment history. The therapy in this case aims to analyze the maintaining features for her depressive complaints, the borderline level personality organization, and help her to show improvements in interpersonal area, which were expected to led improvements in her complaints.
\end{abstract}

Keywords: Sullivan, corrective emotional experience, borderline organization, depressive symptoms. 


\section{Sınırdurum Kişilik Organizasyonunun ve Depresif Semptomların Sullivan’ ın Kişilerarası Teori'si Açısından Yorumlanması: Terapistin Katılımcı Gözlemci Rolü}

Sınırdurum kavramı pek çok tanı kılavuzunda kişilik bozuklukları başlığı altında tanımlanmaktadır (Amerikan Psikiyatri Birliği, APA, 1994). Sınırdurum Kişilik Bozukluğu (SKB) terimi ilk olarak 1938 yılında, Adolph Stern tarafindan nevrotik ya da psikotik durumlarla tanımlanamayan bazı ara grup özellikler sergileyen hastaların durumunu tanımlamak için kullanılmıştır. Tanımlayıcı özelliklerinin benzerliklerine göre kişilik bozuklukları Tanı Ölçütleri Başvuru El Kitabının 5. basımında (DSM-5) üçe ayrılmıştır (APA, 2013). Sınırdurum kişilik bozukluğu DSM-5' de kısaca istikrarsız kişilerarası ilişkiler, kendilik imajı ve duygulara ek olarak dikkate değer dürtüsellik ile tanımlanmıştır (APA, 2013). Gerçek ya da hayal edilen bir terk edilme duygusundan kaçınmak için sarf edilen aşırı çaba, istikrarsız kendilik algısı, artan dürtüsellik hali, kendine zarar verme davranışları, duygusal istikrarsızlıklar, asabiyet ve dönemsel strese de bağlı paranoid düşünceler ve dissosiyatif semptomlar sınırdurum kişilik bozukluğu hastalarının özelliklerini açıklamaktadır (APA, 2013).

Sınırdurum kavramı bu makalede McWilliams'ın yaklaşımda belirtilen şekilde kişilik organizasyonunda bir seviyeyi tanımlamaktadır (2011, s.53). McWilliams'a göre bireyin kişilik yapısı kişilik örgütlenmesinin gelişimsel düzeyi ve bu düzey içindeki savunmacı tarz şeklinde iki farklı ancak etkileşim halindeki boyuttan oluşmaktadır. Birinci boyut, kişinin bireyleşme seviyesini veya patoloji seviyesini, gelişimini “psikotik, sınırdurum, nevrotik” olmak üzere üç farklı şekilde kavramsallaştırmaktadır. İkinci boyut ise; kişinin karakter tipini "paranoid, depresif, şizoid, narsist" ve benzeri şekilde tanımlamaktadır (McWilliams, 2011, s. 51). Sınırdurum seviyesinde kişilik organizasyonuna sahip olan kişilerin, kimlik bütünleşmesinde problemler yaşadığı bilinmektedir. Bu problemler kendisini tutarsız ve hızlı değișen kendilik deneyimleri ile göstermektedir. Sınırdurum kişilik örgütlenmesindeki kişilerin kullandıkları inkâr, yansıtmalı özdeşim, bölme ve değersizleştirme gibi ilkel savunma mekanizmaları da dikkat çekicidir (McWilliams, 2011, s.74). Sınırdurum kişilik örgütlenmesine sahip kişinin terapiden beklentisi, yaşamakta olduğu acının çok hızlı bir şekilde dindirilmesidir. Ancak bu beklentiye zıt olarak, kimlik bütünleşmesindeki problemler, çift değerliğe ve belirsizliğe karşı tahammülsüzlük ve gözlemleyen egonun eksikliği gibi sebeplerle terapistin yardım amaçlı müdahalelerini saldırı olarak algılamaktadır. Aynı zamanda bu alg1, sınırdurum örgütlenme seviyesindeki kişinin kişilerarası ilişkilerinde sorun yaratan öfkeli, düşmanca tavır ve tutarsız duygu değişimlerinin de kaynağıdır (McWilliams, 2011, s.75).

Sınırdurum kişilik örgütlenmesinde, kişilerarası ilişkilerde belirgin olarak gözlemlenen yaklaşma ve kaçınma döngüsü, Masterson (1976) tarafından açıklanmıştır. Bu döngüde kişi ilişki içinde olduğu bir insana yakınlaştığını hissettiğinde yutulma ve tamamen kontrol altına girme korkusuna kapılmaktadır. Öte yandan, bu kişiler ilişki içinde yalnız ya da uzaklaşmış hissettiklerinde ise, travmatik bir terk edilme duygusu yaşamaktadırlar. Bu durum ise, terapi odası içinde ve dışında kurulan tüm kişilerarası ilişkilerde gözlenebilen, sürekli bir yaklaşma ve uzaklaşma döngüsüne yol açmaktadır (Masterson, 1976, p.75).

Sınırdurum seviyesinde örgütlenen kişiliğin özellikleri ile depresif semptomlar birbirini tekrarlayan biçimde işleyerek birbiriyle özdeşleşmektedir (Beatson ve Rao, 2012). Bu birlikte işleyiş hali de kişilerde yalnızlık, izole olma, boşluk hisleri, terk edilme korkusu, öfke ve nefret gibi 
olumsuz duyguların oluşmasına neden olabilmektedir (Leichsenring, 2004). Gunderson (1996) da araştırma sonuçlarında sınırdurum seviyede görülen depresif semptomlar sonucunda en çok kişilerarası ilişkilerin bozulduğunu belirtmiştir. Bu kişilerin önem verdikleri bir ötekinin yokluğunda çok kırılganlaştıkları ve yoğun bir şekilde yalnız, terk edilmiş ve boşlukta kalmış hissettikleri görülmektedir. Bu sebeple depresif semptomlar ile sınırdurum seviyesinde kişilik organizasyonunun tedavi planlamasında, sadece depresif yapının değil, mutlaka sınırdurum yapının da çalışılacağı bir tedavi planlanmalıdır (Gunderson, Morey ve Stout, 2004). Yapılan araştırmalarda bu yapının birlikte çalışılabilmesi için en etkili yöntemlerden birinin, ilaç tedavisi ile birlikte yürütülen kişilerarası yaklaşıma dayalı psikoterapi olduğu görülmektedir (Bozzatello ve Bellinno, 2016).

Amerikan Kişilerarası yaklaşım ve İngiliz Nesne İlişkileri teorisyenleri kişilerarası ilişkiler üzerine incelemeler yapmanın, ilişkilenme biçimi ve bağlanma tarzına dair bilgiler toplamanın, şuan yaşanmakta olan şikâyeti daha iyi analiz edebilmek için kaynak sağlayacağı görüşünü desteklemektedirler. Özellikle vakanın kavramsallaştırılmasında, bağlanma tarzının ve ayrılmabireyleşme meselelerinin önemini vurgulamaktadırlar (McWilliams, 2011, s.64). Bu yaklaşımlarla paralel şekilde, Erickson da teorisinde, terapide öncelikle güven ve güvensizlik meselelerine, ikincil olarak ayrılma ve bireyleşme meselelerine, ardından ise özerklik, utanç, kuşku, girişimcilik ve suçluluk gibi duygusal yapılarına odaklanılması ve çalışılması gerektiğini vurgulamıştır (McWilliams, 2011, s.64). Tüm bu bilgiler 1şığında, kişilerarası ilişkilerin tedavi sürecinde işlenebilecek en temel alanlardan biri olacağı söylenebilir.

Kişilerarası teorinin de temel aldığı, ilişkisel modelin diğer pek çok psikanalitik modelden ayrışan yanı, Freud'un dürtü kuramını reddeden yaklaşımıdır. Freud'un teorisinde cinsel ve agresif dürtüler insan davranışının temel enerji kaynakları olarak görülmekte iken, ilişkisel teoride bu motivasyon kaynakları kişinin çevresiyle ilişki kurmaya ve ya iletişime geçmeye duyduğu ihtiyaç olarak tanımlanmaktadır (Mitchell, 2009, s.4). Kişilerarası teori Harry Stuck Sullivan'ın şizofreni hastalarıyla yürüttüğü çalışmalarının sonucu olarak 1920li yıllarda ortaya çıkmıştır. Sullivan’ a göre (1953) kişilik, "kişinin hayatını karakterize eden ve tekrarlayan kişilerarası ilişkilerle oluşan kalıcı yapıdır”. Kişilerarası teoride kişilik, kişilerarası ilişkilerden ayrı tanımlanamayan hipotetik bir kavramı tanımlamaktadır (p.111). Bahsi geçen kişilerarası ilişkilerin tanımında gerçek bir ötekiye her zaman ihtiyaç duyulmamaktadır. Örneğin, kişi bir halk kahramanı ya da hayali bir karakter ile de etkileşim oluşturabilir. Hatta öteki ile ilişkinin yansımasını içerdiği için sadece hatırlamak, hayal etmek, gündüz düşleri kurmak ya da düşünmek bile birer kişilerarası etkileşimdir (Hall ve Lindzey, 1964, s.137). Öte yandan, Sullivan (1953) teorisinde kaygının (gerilimin) kişiliğin oluşumunda ve kişilerarası ilişkilerin de içinde yer aldığı çevreyle kurulan tüm etkileşimin yapılandırılmasında temel bir rolü olduğundan bahsetmiştir. Sullivan teorisinin içinde kaygının operasyonel tanımını direk olarak yapmak yerine, bu kavramı etkileri üzerinden açıklamıştır(s.205). Mitchell ve Black (1995) fiziksel ve zihinsel ihtiyaçların ötekinde karşılıklı bir tepki oluşturduğunu ve amacın zaten gerilimi azaltmak olduğunu belirtmiştir. Sullivan da sabır göstermenin, temas sağlamanın ya da bakım vermenin aslında yetişkin için de tamamlayıcı ihtiyaçlar olduğunu ve yetişkinlerin etkileşimlerini bu şekilde doyurucu kılabileceklerini belirtmiştir (1953). Kişilerarası teoride dinamizm kavramı "bir bireyi karakterize eden spesifik ve yineleyen davranışlar" olarak tanımlanmaktadır (Sullivan, 1953, s.103). Bu teoride dinamizmler iki temel grupta kategorize 
edilmiştir. Birinci gruptaki ayrıştırıcı dinamizmler içinde bulunulan durumdan kopmaya sebep olup, kaygıyı tetiklerken, bağlayıcı dinamizmler, durum ile bir bütünleşme sağlayıp, gerilimi azaltmaktadırlar (s.66). Teoride kişileştirme (personifikasyon), bireyin ihtiyaçları ya da gerilimleri üzerinden edindiği, kendisine ya da ötekilere ilişkin tüm duygularını, tutumlarını ve algılarını içeren imgelerdir. Örneğin "iyi anne" kişileştirmesi anneye ait olan bakım veren, ilgilenen ve bütünleşmeyi çağıran olma özelliklerini içermektedir. Öte yandan bu kişileştirme anneye de bebeğin tüm ihtiyaçlarını karşılayabilmek için gerekli enerjiyi sağlayabilmektedir (Sullivan, 1953, s.112). Buna karşılık olarak da "kötü anne" kişileştirmesi, diğer anneden tamamen ayrılarak, anne ile ilgili tüm gerilim yaratan etkileşimleri çatısı altında toplayabilmektedir. Ancak bu kişileştirmelerin birleştirilememesi kişinin ilerideki kişilerarası ilişkilerinde de sorunlar yaracaktır (Hall ve Lindzey, 1964, s.140).

Sullivan kişilik hakkındaki bilgilerinin çoğunu şizofreni hastalarıyla yaptığı çalışmalardan edinmiştir. Burada ilişkinin önemini tartışırken, "hasta ve terapist arasındaki alanda yüz yüze iken oluşan tüm durumları içinde barındıran bir kişilerarası etkileşim” olarak tanımladığı psikiyatrik görüşme kavramını gündeme getirmiştir (1953, s.381). Sullivan (1953) kişilerin geçmişte kurdukları ilişkilerin güncel ilişki üzerindeki etkilerini "parataksik çarpıtmalar” olarak tanımlamaktadır. Tam da bu noktada, Sullivan bu parataksik çarpıtmaların yetişkinlik döneminde kurgulanan yeni doğrulayıcı duygusal deneyimler ve kişilerarası ilişkiler ile olumlu ya da olumsuz yönde değiştirileceğini belirtmiştir (akt. Stuart ve Robertson, 2012, s.10). Sullivan'ın bu söylemlerinin aynı zamanda Bowly’nin (1977) “temsili model” kavramı ile örtüştüğü görülmektedir. Her iki teorisyen de hasta ve terapist arasındaki ilişkinin, kişinin çarpıtmalarının yerine yeni ve doğrulayıcı deneyimler sağlamada işlev kazanabileceğini ifade etmişlerdir. Bu anlamlandırma, aktarım ve karşı aktarımın yorumlanması yoluyla örtük bir biçimde ya da hastaya tepkilerinin direkt sorulması yoluyla açıkça yapılabilmektedir (Stuart ve Robertson, 2012, s.11). Sullivan (1953) çalışmalarında bir terapistin tedavi sürecinde kesinlikle bir gözlemciden daha etkin bir katılımcı rolü olduğunu fark etmiştir (Hall ve Lindzey, 1964, s.147). Tüm bu söylemler terapi odasına taşındığında, terapistin danışan ile yaşantısında hem bir katılımcı olarak tüm süreci kendi özellikleri ile yaşantılayan, hem de bir gözlemci olarak bu ilişkiyi hastanın tarihçesi çerçevesinde de gözlemleyen bir rolü taşıdığı görülmektedir. Bu bilgiler ışığında, bu makalede sınırdurum kişilik örgütlenmesinde depresif semptomlar sergileyen bir vaka Sullivan'ın kişilerarası teorisi temelinde ele alınmıştır.

\section{Buket Hanım}

Buket Hanım 30 yaşında, iki çocuklu emekli bir anne ile işçi bir babanın, büyük çocuğudur. Genel olarak iş koşullarından şikâyetçi olan Buket Hanım, daha iyi koşullarda çalışmayı hak ettiğine inanmasına rağmen, kendisinin bu konuda bir girişimi bulunmamaktadır. Buket Hanım AYNA Klinik Psikoloji Destek Ünitesine de depresif atakları nedeniyle başvurduğunu belirmiştir. Güncel olarak yaşadığı sorunlarla baş edemediği için ve yeterince sorumluluk almadığını düşündüğü için de suçlu hissettiğini aktarmıştır. Özellikle kariyer planları ve romantik ilişkiler başta olmak üzere hayatının pek çok alanında yaşadığı kararsızlık hissinden şikâyetçi olan Buket Hanım, bu durumun hem fiziksel hem de zihinsel anlamda kendisini yorduğunu belirtmiştir. Tüm bu şikâyetler Buket Hanım'ın hayatında günlük yaşamını sürdürmesinde de zorluklara neden olmaktadır. Daha önceki terapi süreçleri bazen terapist kaynaklı bazen ise kendi tercihiyle 
sonlanmıştır. Sonlandırılmış olan terapi süreçleri ele alınırken, Buket Hanım’ın eski terapistlerine karşı halen öfkeli ve üzgün olduğu gözlemlenmiştir.

Buket Hanım, kendisinin başvuru sebebi olan depresif atakları, kişilerarası ilişkilerde güçlükler yaşadığı dönemlerde ortaya çıkan, sosyal içe çekilme ve aşırı uyku gibi fiziksel yorgunlukla kendisini gösteren, aile ve sosyal hayatının akışını bozan dönemler olarak tanımlamıştır. Ek olarak, Buket Hanım depresif yakınmaları dâhilinde kendiliğine dair olumsuz algısı ve düşünüş tarzından da bahsetmiştir. Bu düşünüş tarzında yaşadığı olumsuzlukları felaketleştirerek yaşamını daha da çekilmez kıldığını fark ettiğini de paylaşmıştır. Buket Hanım kliniğimize depresif semptomları ile başvurmuş olmasına karşın, ardından problemli kişilerarası ilişkiler, fiziksel şikâyetleri gibi konularda terapide ele alınmıştır.

\section{Terapi Süreci}

Terapist, Buket Hanım'ın kendiliğinin gelişimine ve bütünleştirilmesine yönelen yolculuğunda ona eşlik etmeye çalışmıştır. Bu yolculuğun sonunda Buket Hanım'ın gelişen gözlemleyen egosu ile kişilerarası ilişkilerini ve kaygılarını düzenleyebildiği bir hayata ulaşması amaçlanmıştır. Terapi sürecinin merkezinde Buket Hanım ile terapist arasında oluşan güvenli ve anlamlı ilişki yer almıştır. İlerleyen seanslarda Buket Hanım ve terapist arasında kurulan ilişki; olumlu iletişim, tutarlı pozisyondaki öteki, sağlıklı sınırlar ve yeni doğrulayıcı duygusal deneyimlere dair örnek oluşturmuştur. Terapist ile danışan arasında kurulan ilişki sürecinde, Buket Hanım'ın tarihçesinde yer alan pek çok durum etkili olmuştur. Örneğin, danışanın, annesi ile ilişkisinde yaşadığı ayrılma kaygılarının bütünleştirici bir yapı yerine kaygıyı artırıcı, görece tehdit unsurları içeren bir yaklaşım ile karşılanması, yeni bir ilişki kurma sürecinde zorlanmasında etkili olmuştur. Danışan özerk olmaya yakınlaştığı anlarda en güvenilir bulduğu kişiler olan ailesinin bile yanında olmayacağına dair deneyimler edinmiştir. Tüm bu deneyimlere karşı, Buket Hanım'ın güvenmeyi ve ilişki kurmayı tercih ettiği ilişkili oluşmuştur. Ancak, eski terapisti, ile kendisi açısından yarım kalarak sonlanan terapi süreci ve eski nişanlısı ile sonlandırmak zorunda olduğunu ifade ettiği ilişkisi, tekrar kaygı ve kaçınma düzeyini artırıcı yaşantılar olarak yer etmiştir. Seans içinde bu konu ele alındığında danışan her bağın kaybedilme ihtimali olduğunu ve bu ihtimal ile yüzleşmekten korktuğu için yeni bir bağın kurulmasına izin vermeyerek, yalnız kalmayı tercih ettiğini belirtmiştir. Buradaki kaygı ve kaçınma hali terapist ile danışan arasındaki ilişki alanında, danışanın, terapistin kalıcılığını test ettiği denemeleri üzerinden çalışılmıştır.

Örneğin, danışan, terapi sürecinde psikiyatr görüşü talep edildiğinde, terapi seanslarını aksatıp, ardından eski terapisti (aynı zamanda psikiyatristi) ile görüşmüştür. Bu görüşmenin ikili ilişkiye etkisi ele alındığında, danışanın terapistin tepkilerine dair beklentileri ve kaygıları olduğu fark edilmiştir. Bu deneyimde, danışan suçlu hissetmeden, ihtiyacını ve niyetini anlamaya yakınlaşmıştır.

Buket Hanım'ın kişiliğinde görülen hızlı değişimler, kişilerarası ilişkilerdeki bozulmalar, ani duygu değişimleri gibi semptomları ve idealizasyon, değersizleştirme, yansıtmalı özdeşim gibi kullandığı savunma mekanizmaları kişiliğinin sınırdurum seviyesinde örgütlendiğini düşündürmüştür. Görüşmelerde gündemlenen stres yaratabilecek konulara dissosiye yaklaşım tarzı ve savunmaları ile yüzleştiğinde öncelikle öfke, ardından dağılma tepkisi vermesi de sınırdurum seviyesinde yapılanma tezini güçlendirmiştir.

Seanslarda ayrılma bireyleşme teması çerçevesinde, danışanın aile evinden ayrılma isteği 
ele alınmaya başlandığında, danışan evde yaşadığı bir tartışma sonucu ani bir evden ayrılma kararı almıştır. Bu davranış bir yandan Buket Hanım'ın özerk bir hayat sürebilmek için ailesinden ayrı yaşamak isteğini gösterirken, öte yandan danışanın ailesi tarafından terk edilme korkusunu ve kendi yetersizliğine yönlendirdiği atıflarını alevlendirmiştir. Seans içerisinde bu akış danışanın ihtiyaçları temelinde ele alındığında, ailesine ihtiyaç duyan yanlarını değersizleştirmiş, yalnız yaşayan insanları idealize etmiştir. Savunmalarının arkasında kalan istek, ihtiyaç ve kaygıları ele alınmaya çalışıldığında ise, Buket Hanım duygu ve düşüncelerini ancak yazarak ve üçüncü bir kişinin yaşantıları şeklinde dile dökebilmiştir. Sınırdurum seviyesinde kişilik örgütlenmesi ve depresif yapılar ile de tutarlı olarak, danışanın ayrılma bireyleşmesinde tekrarlayan yapısı pek çok ilişkisinde gözlemlenmiştir. Bu yapıda Buket Hanım, kendisi ve ilişkilendiği kişi ya da kişiler arasına her mesafe koyduğunda terk edilme korkusu yaşadığını; anlamlı ve derin bir ilişki kurmak için yakınlaştığında ise yutulma korkusunu duyduğunu belirtmiştir. Halen, kendi evinde kaldığında ailesinden uzakta ve dışarıda kalmış hissederken; ailesinin evinde kaldığında ise yoğun bir baskı hissettiğini ve sınırlarının belirsizleştiğini belirtmiştir.

Tarihçesinde kendiliğini korumak için Buket Hanım'ın "iyi psikiyatr”, "kötü ilaçlar” ya da "yetersiz Buket” gibi bazı kişileştirmeler geliştirdiği görülmüştür. Bu kişileştirmeleri sürdürebilmek için Buket Hanım bazen gerçeği çarpık olarak algılamakta ve davranışlarını da bu çarpıtılmış algıya göre şekillendirmiştir. Hatta bu kişileştirmeleri koruyabilmek için Buket Hanım kendiliğini bile değersizleştirmiştir. Bahsi geçen yapıların tek yönlü değer algısı, Buket Hanım'ın çift değerliliğe karşı hassasiyetini de açıklamıştır. Bu sebeple de Buket Hanım'ın sevilen ve nefret duyulan özellikleri bir kişide ya da yapıda birleştiremediği gözlemlenmiştir. Ancak sevmediği ya da nefret ettiği özellikleri olan bir kişinin, aynı zamanda hayatında yaşamsal bir değeri olduğunda, Buket Hanım duygu ve davranışlarını düzenleyememiş ve tutarsız tavırları tüm kişilerarası ilişkilerinde sorun yaratmıştır. Örneğin, şikâyetçi olduğu alanlar incelenirken, sorunlarına dair hızlıca kendisini suçlu ilan ettiği gözlemlenmiştir. Seans içerisinde suçlu aranmadığı ve yapının anlaşılmaya çalışıldığı, öfkeyi kendisine yönlendirmesinin anlamı ile birlikte ele alındığında ise, ailesine ani bir öfke ortaya çıkmıştır. Ancak bu öfke, sevdiği ebeveynlerine yönelemediği için, bu fikre sahip olmanın da katladığı suçluluk ile tekrar kendisine dönmüştür. Ailesinin hem sevdiği hem de öfkelenebileceği yanlarını birleştirmekte oldukça güçlük çekmiştir.

Güvenilir bir terapi ilişkisinin kurulmasında, Buket Hanım'a özgü birçok özellik, istek ve ihtiyacın hem pekiştirici hem de zorlayıcı şekilde etkili olduğu gözlemlenmiştir. Buket Hanım'ın tutarlı ve kalıcı ötekilere duyduğu ihtiyaç oldukça belirgin şekilde seanslarda ortaya çıkmıştır. Bu ihtiyaçlarının kurulan ilişkide karşılanıp karşılanamayacağını anlamaya çalışan Buket Hanım, pek çok kez terapi ilişkisini test etmeyi denemiştir. Terapistin yetkinliğine getirdiği eleştiriler, terapistin medeni hali ve benzeri özelliklerinin farklılığı üzerinden getirdiği anlaşılamayacağına dair inancı ve terapi ilişkisini sadece maddiyata dayalı gördüğünü, gerçek bir ilişki olmadığını belirtmesi gibi durumlar bu denemelere dair örnekler arasında yer almıştır. Bu denemeler sırasında danışanın yakınlık kurmaya dair gerilimlerinin ve öte yandaki terk edilmeye dair korkularının en rahat öfke ile ifade bulabildiği görülmüştür. Ancak süreç içerisinde Buket Hanım, tüm olumlu ve olumsuz duygularını, isteklerini ifade ettiğinde bile kalıcı ve tutarlı olan bir öteki ile ilişki yürütmeyi deneyimlemiştir. Buket Hanım'ın şikâyetçi olduğu alanlardaki istek, dilek ve ihtiyaçları üzerinde çalışabilmek için, çevresiyle etkileşimleri hakkında bilgi toplanmaya çalışılmıştır. Süreç içerisinde 
terapist ve Buket Hanım arasında daha güvenli ve derinlikli bir ilişki oluştuğunda, problem alanlarının terapi ilişkisi üzerinden anlaşılması ve çalışılabilmesi daha mümkün hale gelmiştir. İlerleyen seanslarda artık Buket Hanım terapiye kendi yaşantısında sorun yaşadığı meseleleri daha fazla yansıtmaya ve seanslara veri sağlamaya başlamıştır. Örneğin, terapistin yetkinliğini sıklıkla eski terapisti ile kıyaslayarak, eski terapistinin kendisi için daha önde olduğuna dair söylemlerde bulunmuştur. Bu söylemler ve yarattığı rekabetin anlamı çalışıldığında, danışanın da kız kardeşi ile rekabetine dair hisleri de gündeme gelebilmiştir. Buket Hanım bu rekabete giremeyeceğinden, ailesinin gözünde ne şekilde geri kaldığından da bahsedebilmiştir. Danışanın kendisi için gündeme getirilmesi güç duyguları terapistte uyandırarak, bunları konuşulabilir hale getirmesi, bu duyguyu öncelikle terapiste yansıtmasının kendisi için savunma işlevi fark edilmiştir. Terapi ilişkisi içinde Buket Hanım, istek ve ihtiyaçlarını açık bir biçimde ifade ettiğinde, bunların olumlu bir atmosferde karşılanmasını deneyimlemeye başlamıştır. Bu açıklık kendisinin kırılgan ve hassas yanlarını sergileyebilmesi için de firsat oluşturmuştur. Terapi ilişki içinde daha önce Buket Hanım'ın tarihçesinde tekrarlayan yapıların, terapi odasında oluşan örnekleri çalışılmıştır. Yeni yeni deneyimlediği bu açıklık Buket Hanım'da gerilim de yaratmıştır. Baş etmekte güçlük çektiği duygu ve düşüncelerini terapistin içinde yaratmaya çalışarak, bunları terapiste fark ettirmeye çalışmıştır. Terapist, içinde bulunduğu sürecin, kendisinde uyandırdı̆̆ı duyguları, kendi katılımdan gelen payı ve Buket Hanım'ın sürecinin akışını gözlemlemiştir. Süreç içerisinde, terapist kendi duygularını fark etmek ve işlemlemek konusunda gelişmiştir. Terapistin süreç içerisindeki kendi payı ile danışana dair alanları ayrıştırmasında ve katılımcı gözlemci rolünde, kendi duygularına bakabilmesi ve duygularına yakınlaşması önemli bir rol oynamıştır. Buket Hanım'ın da bu yaklaşık bir yıllık süreç içerisinde bu yeni ilişki içindeki deneyimlerinin katkısıyla duygularına, istek ve ihtiyaçlarına bakabilmek konusunda geliştiği ve kendiliğine yakınlaştığı gözlemlenmiştir. Ancak güvensizliğinin dayandığı derin kökenleri nedeniyle, sağlam bir zemin oluşturması, buna inanması ve bunun üzerinde kendiliğini geliştirmesinin zaman aldığı görülmüştür.

Özet olarak bu makalede, uzun süredir devam eden depresif semptomlar ve sınırdurum seviyede kişilik örgütlenmesi özellikleri ile kliniğimize başvuran Buket Hanım, Sullivan'1n (1953) kişilerarası teorisi çerçevesinde ele alınmıştır. Süreç içerisinde en aktif işleyen sistem teorinin katılımcı gözlemci pozisyonu olarak önerdiği sistem olmuştur. Yürütülen terapi süreci, hem terapistin hem de Buket Hanım'ın aktif bir katılımcı olarak yer aldığı ve bunun yanında terapistin sürecin dışındaki gözlemcisi olarak da pozisyon aldığı bir akışı içermektedir. Seanslar içerisinde depresif semptomlarının anlamı ve kendisi için işlevi, bunların sınırdurum yapısı ile örtüşen ve birbirini döndüren özellikleri ele alınmaya çalışılmıştır. Şikâyetçi olduğu ve kendisinde gerilim yaratan tüm olayların ele alınışı ve kendiliğini tehdit altında hissettiğinde kullanmaya yöneldiği savunmalar Buket Hanım'ın terapist ile ilişkisi çerçevesinde ele alınmıştır. Rekabet, yetersizlik, ilgi ihtiyacı, görülme ihtiyacı ve korunma arzusu ile ilgili yapıları terapi ilișkisinde terapist ile ilişkilenme biçimi üzerinden deneyimlenmiş, gözlemlenmiş ve işlenmiştir. Bu yapılar terapi ilişkisinde, yeni bir çevre ve yeni bir öteki ile yeniden yapılandırılmaya çalışılmıştır. Önümüzdeki süreçte de Buket Hanım'ın kendisini gözlemlediği ve kişilerarası etkileşimlerini, çevresini ihtiyaçlarına göre düzenleyebildiği bir sistemin yapılandırılması planlanmaktadır. 


\section{Kaynakça}

American Psychological Association (2013). Publication manual of the American Psychological Association (5. bask1.). Washington, DC:APA.

Beatson, J. A., \& Rao, S. (2012). Depression and borderline personality disorder. The Medical Journal of Australia Open, 1(4), 24-27. doi: 10.5694.

Bozzatello, P., \& Bellino, S. (2016). Combined therapy with interpersonal psychotherapy adapted for borderline personality disorder: A two-years follow-up. Psychiatry Research, 240, 151156. doi: 0165-1781.

Gunderson, J. G. (1996). The Borderline Patient's Intolerance of Aloneness: Insecure Attachments and Therapist Availability. The American Journal of Psychiatry, 153, 752-758.

Gunderson, J.G., Morey, L.C., Stout, R. L., Skodol, A.E., Shea, M. T., McGlashan, T. H., .. . Bender, D. S. (2004). Major Depressive Disorder and Borderline Personality Disorder Revisited Longitudinal Interactions. Journal of Clinical Psychiatry, 65(8), 1049-1056.

Hall, C. S. \& Lindzey, G. (1964). Theories of personality. New York, London: John Wiley \& Sons Inc. Leichsenring, F. (2004). Quality of depressive experiences in borderline personality disorder: Differences between patients with borderline personality disorder and patients with higher levels of personality organization. Bulletin of the Menninger Clinic, 68(1), 9-22.

Masterson, J. F. (1976). Psychotherapy of the borderline adult: A developmental approach. New York: Brunner/Mazel.

Mitchell, S. A. \& Black, M. J. (1995). Freud and beyond A history of morn analytic thought. New York: Basic Books.

Mitchell, S. A. (1988). Relational Concepts in Psychoanalysis An Integration. United States of America: Harward University Press.

McWilliams, N. (2011). Psychoanalytic Diagnosis Understanding Personality Structure in the Clinical Process (2. basim). New York, London: The Guilford Press.

Stern, A. (1938). Psychoanalytic investigations of and therapy in the borderline group of neuroses. Psychoanalytic Quarterly, 7, 467-489.

Stuart, S. \& Robertson, M. (2012). Classics in Psychotherapy Interpersonal Psychotherapy a clinician's guide (2. bask1). Boca Raton: CRC Press, Taylor and Francis Group.

Sullivan, H. S. (1953). The Interpersonal Theory of Psychiatry. Perry, H. S., Gawel, M. L. \& Cohen, M. B. (Ed.). New York: The William Alanson White Psychiatric Foundation, W.W. Norton \& Company Inc. 